\title{
Prescient marine champion
}

\section{The Human, the Orchid and the Octopus: Exploring and Conserving our Natural World \\ by Jacques Cousteau \& Susan Schiefelbein Bloomsbury USA: 2007.320 pp. $\$ 25.95$}

\section{Ken Collins}

Jacques Cousteau turned the television screen into a porthole onto the underwater world and each of his documentaries attracted some 250 million viewers worldwide. It was his idea to put a yellow stripe down the arms and legs of early wetsuits to make divers more visible on film. He was the reason I became a marine scientist.

Ten years before his death in 1997, Cousteau wrote The Human, The Orchid and The Octopus, now available for the first time in English, in collaboration with Susan Schiefelbein. She had worked alongside him and written the scripts for many of his films, and has since added a biographical introduction that gives us an insight into the development of Cousteau's views on conserving the marine environment, which forms the main subject of the book. It is a very readable mix of stories of underwater exploration, overlaid with an increasing awareness of environmental issues and an emerging philosophy that will be widely appreciated.

The book's mysterious title derives from the last chapter — 'The miracle of life' — which discusses the most highly developed examples of vertebrates, plants and invertebrates. In this chapter, Cousteau's fascination with the complexity of marine life is illustrated by his delight in discovering and understanding the behaviour of small fishes - for example, the habit of the perch-like wrasse of laying its eggs in the bowls of sponges. He was tickled by an example of native wisdom in Indochina during his early navy career, when a rower slid over the side of their boat to grab edible evidence that the local fish took a midday siesta. To satisfy his huge curiosity, Cousteau undertook many hair-raising dives, including an early, extremely deep journey in a bathyscape submersible; his definition of a successful dive soon came to be one that returns to the surface.

Wonder at the marine environment led to his concern for its protection, long before it became a global issue. He publicly renounced spear-fishing in 1960, proclaiming that "we must have a fundamental respect for nature". Soon afterwards, he mobilized 11,000 compatriots to prevent a train from delivering its load of radioactive waste for dumping in the Mediterranean Sea. Later, the Madrid Protocol was drawn up as a direct result of his personal plea to world leaders for international protection of the Antarctic continent.

As an experienced marine scientist and director of Monaco's Oceanographic Museum, Cousteau fully understood the risks posed by

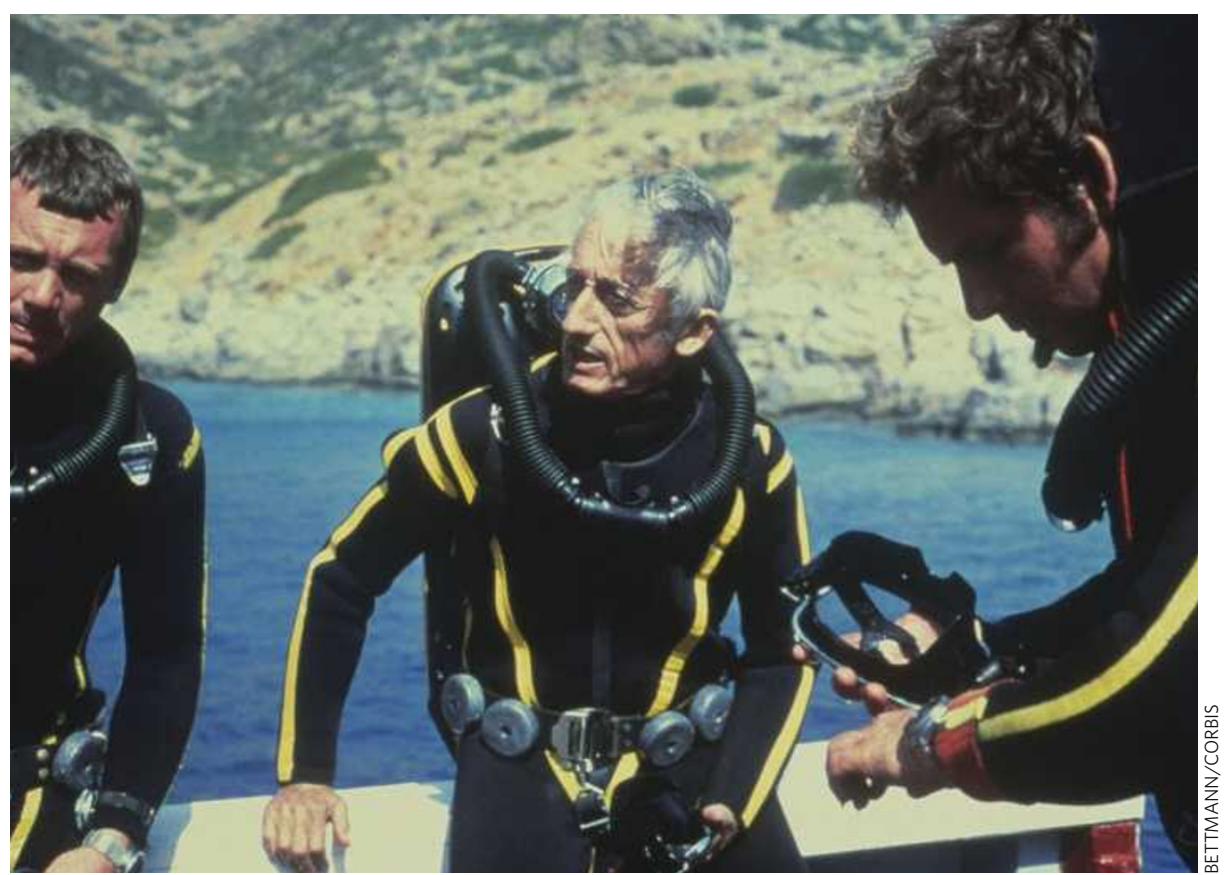

Jacques Cousteau, centre, was a pioneer in protecting the seas from human harm.

pollutants. In the book, this awareness is presented alongside discussion of the world's scriptures, in which water is revered for its bounty and its purity. As Cousteau became more caught up in conservation issues, he realized that policy decisions are too frequently dictated by market, rather than human, values. Schiefelbein adds an epilogue updating many of the environmental issues discussed.

Despite the age of the core text of The Human, The Orchid and The Octopus, the issues discussed are still topical. Cousteau observes that shallow coastal waters are the most fertile, but also the most vulnerable to human activities. Problems with world fisheries continue to increase. Even at the time of writing, he noted that fish could never feed the world.

Cousteau decries the militarization of science through the cold-war years, which produced the newspaper headline "Fear of Peace Depresses Market". He concludes with the thought that humanity's enemy has never been science, but rather that we need to use science to civilize civilization.

In his foreword, Bill McKibben considers fear to be the second-best motivator for conserving our planet - the most powerful being love for it, as generations learned from Jacques Cousteau.

Ken Collins is a senior research fellow at the National Oceanography Centre, Southampton SO14 3ZH, UK.

\section{Human distilleries}

\section{Rethinking Expertise \\ by Harry Collins \& Robert Evans \\ University of Chicago Press: 2007. 160 pp. $\$ 37.50$}

\section{Robert P. Crease}

The modern world depends on experts and expertise. We use them all the time, without a second thought, in our personal and professional lives. Yet controversies over such matters as the causes of AIDS and global warming, and a growing public distrust of science, provoke scepticism about the abilities and agendas of so-called experts. According to Harry Collins and Robert Evans, the notion of expertise needs an overhaul.

The authors of Rethinking Expertise are both sociologists. Collins came across the topic during his 30-year study of scientists involved with gravitational waves, which culminated in his book Gravity's Shadow: The Search for Gravitational Waves. He decided that the portrayal of experts as knowledge producers who pass on nuggets of truth to clients was woefully inadequate, a point he and Evans presented in a 2002 article reprinted in The Philosophy of Expertise (an anthology that I co-edited). Rethinking Expertise expands on that work, calling for "a new sociology of expertise".

Collins and Evans argue that expertise does 